\title{
Epidemiological Profile of Patients Suffering from Urolithiasis in African Urological Environments from 2016 to 2020
}

\author{
Steve Aristide Ondziel-Opara ${ }^{1,2 *}$, Armel Melvin Ondongo Atipo ${ }^{1,2}$, Ghidmar Onguele Okemba1, \\ Rolland Bertille Banga Mouss ${ }^{1,2}$, Yannick Isjody Dimi Nyanga ${ }^{1,2}$, Anani Wencesl Severin Odzebe1,2, \\ Alain Prosper Bouya ${ }^{1,2}$
}

${ }^{1}$ Department of Urology, Andrology, Brazzaville/Congo University Hospital, Brazzaville, Republic of Congo

${ }^{2}$ Faculty of Health Sciences, Marien Ngouabi University, Brazzaville, Republic of Congo

Email: *sondziel@yahoo.fr

How to cite this paper: Ondziel-Opara, S.A., Ondongo Atipo, A.M., Onguele Okemba, G., Banga Mouss, R.B., Dimi Nyanga, Y.I., Odzebe, A.W.S. and Bouya, A.P. (2022) Epidemiological Profile of Patients Suffering from Urolithiasis in African Urological Environments from 2016 to 2020. Open Journal of Urology, 12, 157-167.

https://doi.org/10.4236/oju.2022.122016

Received: October 7, 2021

Accepted: February 25, 2022

Published: February 28, 2022

Copyright $\odot 2022$ by author(s) and Scientific Research Publishing Inc. This work is licensed under the Creative Commons Attribution International License (CC BY 4.0).

http://creativecommons.org/licenses/by/4.0/

\begin{abstract}
Introduction: Urolithiasis is a very common pathology in the world. Its epidemiological profile varies from one region to another. In Africa in general and in the Congo in particular, it seems to be unknown. Objective: To determine the sociodemographic, diagnostic, therapeutic and evolutionary paraclinical parameters of 167 adult patients with urolithiasis. Patients and Methods: Cross-sectional, descriptive, retrospective study conducted in the urology department of Brazzaville University Hospital over a period of five years. We studied sociodemographic, therapeutic and evolutive. Results: During the study period 167 patients were treated for urolithiasis out of 2236 patients, a hospital frequency of $7.46 \%$. The sex ratio $\mathrm{M} / \mathrm{F}$ was 1.49 . The average age of the patients was 42.05 years. They were overweight and/or obese in $53 \%$ of cases. Workers accounted for $46.53 \%$ of cases, with a low socio-economic level (42.5\%) and a lower level of education (68.31\%). There was a high percentage of complications, dominated by hydronephrosis $(66.33 \%)$ and urinary tract infection (59.4\%). The treatment was surgical in the majority of cases or $74.8 \%$. Thirty-three patients had a lithiasis recurrence, a frequency of $19.7 \%$. Conclusion: Urolithiasis is common. Being overweight is the most found risk factor. Lithiasis recurrence affects nearly one in five patients.
\end{abstract}

\section{Keywords}

Urolithiasis, Epidemiology, Brazzaville

\section{Introduction}

Urolithiasis (UL) is an ancient and widespread pathology in the world [1]. While 
the epidemiological profile and its etiological factors continue to increase [2], its occurrence depends on the health conditions, dietary habits and standard of living of the populations [1].

The prevalence of UL differs from region to region. Indeed, it is $7 \%$ to $13 \%$ in North America, $5 \%$ to $9 \%$ in Europe and $1 \%$ to $5 \%$ in Asia [3]. However, in Africa, its prevalence is little known due to a low attendance of hospital structures and the absence of a study extended to the population [4]. However, several indicators tend to show its increase due to global climate change, increasing socio-economic status, westernization of diet and lifestyle [5].

While several studies in Congo have been conducted in particular on open-air surgery in urolithiasis [6], UL of children [7] and lithiasis of the upper urinary tract [8], however none of them has been devoted to the epidemiological profile of UL. It is in this perspective that we proposed to carry out this study with the objective of describing the epidemiological profile of UL in the urology department of the CHUB.

\section{Patients and Methods}

We carried out a descriptive study with retrospective collection from January 2016 to December 2020, five years in the urology and andrology department of the Brazzaville University Hospital.

Our sample consisted of all patients who had been treated for UL during this period and meeting the inclusion criteria; that is, all patients treated and having at least one imaging examination confirming the diagnosis.

We excluded all patients who were not treated, those whose information was missing from the operating and/or hospitalization records or those without imaging.

The parameters studied were: Socio-demographic i.e. age, sex, body mass index (Classified as follows: Normal: BMI $<25 \mathrm{~kg} / \mathrm{m}^{2}$; overweight: $25-30 \mathrm{~kg} / \mathrm{m}^{2}$, Obesity: $>30 \mathrm{~kg} / \mathrm{m}^{2}$ ), level of education, socio-professional status, place of origin, socio-economic level, Clinical (functional signs related to UL or associated with UL: pain, urination disorders, hematuria, digestive disorder, fever, Previous history and treatments (Hypertension, diabetes, urinary tract infection, other pathologies, family history of UL, physical signs: lumbar sensitivity, bladder globe, pain in the ureteral points, large kidney), paraclinical (ECBU, biological assessment: serum creatinine, azotemia, serum calcium, Urinary Tract Ultrasound, radiography of the urinary tree without preparation (AUSP), A computerized tomography (CT) urogram and intravenous urography (IVU). therapeutic (type of treatment: open surgery, pharmacological treatment, endoscopic treatment), progressive (Uretero-hydronephrosis, urinary tract infection, AORF, pyonephrosis). In the minor, it is the socio-economic level of the parents that has been taken into account, to do this we have used the British classification of economic status taking into account the prestige of the profession [9]. There are thus three categories namely: 
- Category 1: with a high socio-economic level, consisting of groups I (management employees and senior managers) and II (management employees and lower managers);

- Category 2: average socio-economic level, consisting of groups III (intermediate employees), IV (small employers and self-employed workers) and V (lower employees in supervision, crafts and similar trades);

- Category 3: low or low socio-economic level, consisting of groups VI (employees in semi-routine jobs) VII employees in routine jobs) and VIII (never worked or long-term unemployed).

For the retired subject, it is the profession exercised the longest that has been considered.

Data entry and processing was carried out using Epi-info software version 7.2.2.6 and data analysis was carried out on SPSS 22 statistical software. The various tables and graphs were generated using the Microsoft Office Excel 2016 software.

For quantitative variables, we calculated means and standard deviations.

\section{Results}

During the study period, there were 167 hospitalized UL cases out of a total enrolment of 2236 patients, a frequency of $7.46 \%$.

The annual distribution of patients with UL is shown in Figure 1.

The median age of our patients was 41 years and the mean age was $42.05 \pm$ 18.40 years with extremes of 6 and 96 years. This average age was $46.12 \pm 18.27$ years for men and $35.93 \pm 16.61$ years for women, the age group from 30 to 50 years constituted $39.60 \%$ of cases.

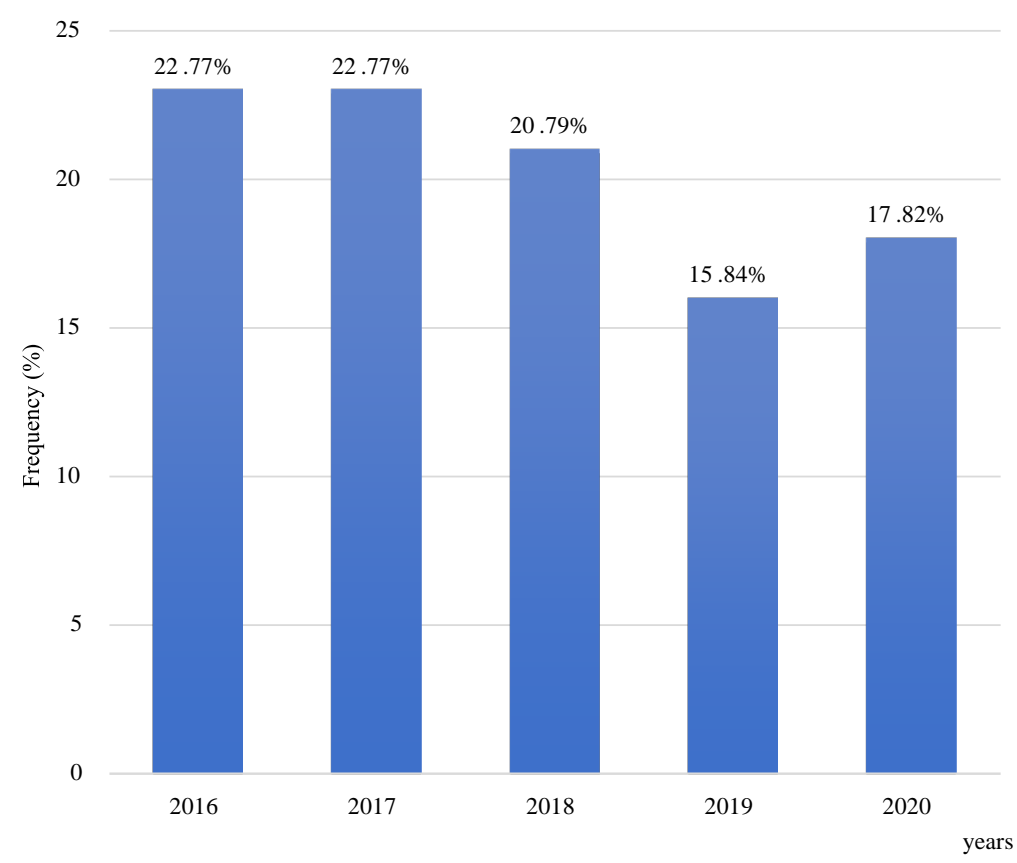

Figure 1. Recruitment of UL by year. 
There were 67 women (40\%) and 100 men (60\%).

The sex ratio $\mathrm{M} / \mathrm{F}$ was 1.49 , varying by the age group (Figure 2 ).

In the male population, the frequency of UL gradually increased to a peak between the age of 40 and 49 (Figure 3 ).

Our population had 120 patients or $71.86 \%$ with a level of education at least at the secondary level and 47 patients or $28.14 \%$ were at most at the primary level.

One hundred and fifty-nine patients or $95.2 \%$ came from the urban area.

Workers made up a workforce of $78(46.7 \%)$ patients, students, retirees and the unemployed made up a workforce of 31 (18.6\%), 15 (9\%) and 43 (25.7\%) patients respectively.

Our population consisted of 19 miners. Of all adult urolithiasis patients, 86 patients $(51.5 \%)$ were single and 62 patients $(37.1 \%)$ were married or common law.

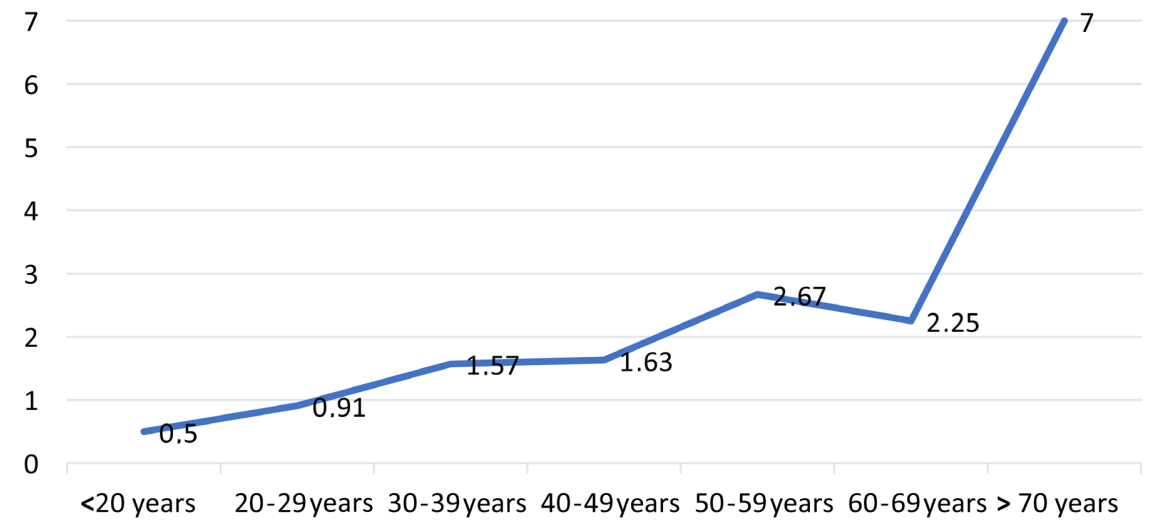

Sex ratio

Figure 2. Change in sex ratio with age group.

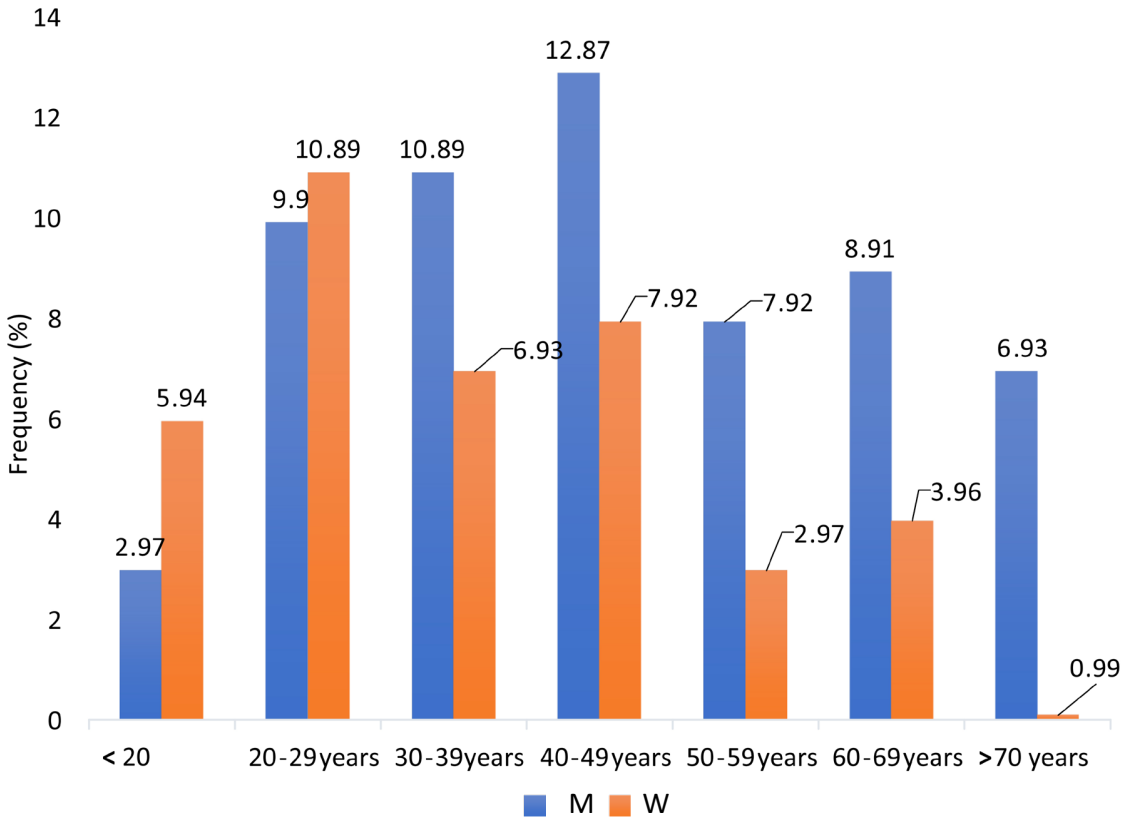

Figure 3. The age and sex distribution. 
Our study population consisted of $42.5 \%$ of patients with a low socioeconomic level, $41.3 \%$ of patients with a medium level and $16.2 \%$ of a high level. In terms of the history, hypertension and diabetes were found in 33 (19.8\%) and 25 (15\%) patients, respectively, repeated urinary tract infections in twelve (7.2\%) patients.

The main symptom was pain regardless of its location. It was renal colic in 117 patients (70\%), hypogastric pain in 24 patients (14.4\%), a lumbar fossa pain in fifteen patients (9\%), and an iliac fossa pain in 2 patients $(1.2 \%)$. Urination disorders were also found; pollakiuria in 46 patients or $27.5 \%$, dysuria in 40 (24\%) patients, urination burns in $27(16.2 \%)$ patients, haematuria in $24(14.4 \%)$ of patients and acute urine retention in 18 (10.8\%) patients. When these signs were accompanied, fever was present in 48 patients or $28.7 \%$, nausea and vomiting in 45 patients (27\%). During the physical examination, a sensitivity of the lumber fossa was found in 99 patients or 59.3\%. Upper, middle and lower ureteral point pain was found in 17 patients (10.2\%), fifteen patients (9\%) and eight patients (4.9\%) respectively. Twenty eight patients (16.8\%) had a bladder globe; 25 patients $(15 \%)$ had an abdominal and/or lumbar scar, and fifteen patients (9\%) had a large kidney.

Urinary Tract without Preparation (AUSP) was performed in 134 patients and demonstrated UL in 111 patients or 79\%. The Urinary Tract Ultrasound was performed in all patients and showed UL in 150 patients, or 90.10\%. Single patients, were noted in 68 patients, or $40.7 \%$. The computerized tomography (CT) urogram was used in 101 patients and found UL in all patients while IVU was performed in 66 patients and diagnosed all patients with UL. The frequencies of patients with two stones and at least three stones were $27.5 \%$ and $31.7 \%$ respectively (46 and 53 patients). The average number of calculations was 2.1 . UL of the upper urinary tract, by far the most represented, was found in 127 patients or $76 \%$ of all UL.

Cystolithotomy was the most performed intervention with 25 cases or $20 \%$ of all patients treated with open surgery, then pyelolithotomy with 31 patients or $24.8 \%$, the then nephrolithotomy and the ureterotomy with respectively 25 patients $(20 \%)$ and 15 patients $(12 \%)$ and finally nephrectomy with 11 patients or $8.8 \%$. Note that 18 cases $(14.4 \%)$ were subjected to double surgery, depending on the location of the LU and the state of the renal parenchymal. After surgery, 5\% of patients presented with a residual stone. There was a high percentage of complications, dominated by hydronephrosis $(66.33 \%)$ and urinary tract infection (59.4\%). Thirty-three patients (19.7\%) had at least one recurrence.

\section{Discussion}

The prevalence of UL has been steadily increasing around the world over the past two decades; but it remains highly variable depending on the geographical location due to multiple factors specific to each culture and race [3].

Romero et al. reported a national prevalence increasing from $3.8 \%$ between 1976-1980 to 5.2\% between 1988-1994 in the United States [10]; Then Scales et 
al. increased this prevalence to $10.6 \%$ among men and $7.1 \%$ among women [11]. Several studies would tend to show in various non-industrialized countries, a gradual evolution of the epidemiological profile of lithiasis patients towards that observed in Western Europe and the United States [12].

This increase is also seen in this study. We obtained a hospital frequency of $7.46 \%$ compared to the previous study conducted by Odzébé et al. which reported a frequency of $7.30 \%$ [6] a slight increase of about $0.16 \%$. Some results in the literature were consistent with ours. Notably Zeng et al. in China [13], Kumari et al. in India [14], Kaboré et al. in Burkina Faso [4] reported a prevalence of $6.4 \%, 7.6 \%$ and $12.52 \%$ respectively. These results can be justified on one hand by the fact that, as in our case, they are countries with a hot and humid climate. Indeed, some studies have proven the correlation between seasonal fluctuations in urinary excretion of calcium and oxalate and the number of hours of monthly sunshine and the occurrence of lithiasic episodes [15]. High temperatures increase insensitivity to sweating, which can lead to more concentrated urine; this event then promotes urinary crystallization and therefore the formation of UL [16].

On the other hand, the majority of our study population came from urban areas where the trend is towards the westernization of eating habits as reported by Loumingou et al. [17].

On the other hand, Mobima et al. in the Central African Republic reported a prevalence of $3.07 \%$ [18]. These results show a lower prevalence than ours and could be explained by the fact that it was a multicentric study because these patients came from different departments of the city for the realization of an ultrasound in their center.

The highest prevalence was reported by Ahmad et al. in Saudi Arabia at 19.1\% [19].

The prevalence and incidence of UL varies enormously by age, with a low frequency in childhood and then rises to peaks between the 4th and 6th decade of life [3].

The average age of our patients was $42.05 \pm 18.40$ years, with extremes of 6 and 96 years. Ten years before our study, Odzébé et al. in Congo had reported an average age of 52.13 years [6]. We have thus noted the current precocity of the occurrence of lithiasis in our population. This was similar to recent data in the literature presenting urolithiasis disease as a condition of young adults [20]. These results were similar to those reported in the African literature. Ze Ondo et al. in Senegal [21], Mobima et al. in the Central African Republic [19] and Omisanjo et al. in Nigeria [22] reported an average age close to ours, i.e. 42.7 years, 40 years and 40.4 years respectively. In the study surgical Management of Urolithiasis of the Upper Tract-Current Trend of Endourology in Africä bringing together several sub-Saharan countries including Congo, Cassell III et al. reported an overall average age of 39.1 years [20]. Kaboré et al. reported the lowest average age in sub-Saharan Africa in 35 years [4]. 
Socio-economic improvement, especially among the youngest strata, could be explanations for this result. This could also be explained by the fact that developing countries, particularly in Africa, have a predominantly young population with a median age often below twenty, unlike Western countries where there was aging population [23]. Ketabchi et al. in Iran reported the lowest average age in the literature in 25.8 years [24].

In our study, of the 167 patients in our study population, there were 67 women $(40 \%)$ and 100 men (60\%) for a sex ratio M/F of 1.49 . The previous study conducted by Odzébé et al. at CHUB reported a sex ratio of 3.25 [6]; compared to ours there is a significant drop in the sex ratio demonstrating that the female subject is increasingly affected by lithiasis disease as reported by Abbassene et al. [25]. Some African authors have found a sex ratio comparable to ours, including Kaboré et al. in Burkina [3], Habbani et al. in Morocco [26].

The same is true elsewhere in the world. Lieske et al. in the United States [27] and Kaulanjan in the French West Indies [28] observed a sex ratio close to ours, i.e. 1.32 and 1.61 respectively.

All these results prove that men are mostly affected by UL than women. The influence of certain sex hormones on certain lithogenic risk factors could be the cause. Indeed, androgens seem to increase unlike estrogens which decrease the urinary excretion of calcium and oxalate, hence the formation of calcium oxalate crystals [29]. However, these results are not fixed. Indeed, we were able to observe a variation in the sex ratio according to age with a tendency to feminization at the beginning of life and then a gradual increase after 20 years until achieving a first peak between 50 - 59 years and a second beyond 70 years when the population was almost exclusively male. Some results in the literature were along the same lines as ours.

Castiglione et al. in Belgium reported a sex ratio of 2.25; with a tendency of sex equalization before 15 years and then a significant increase after this age, before falling in geriatric subjects [30]. The trend towards the equalization of numbers in the 2 sexes or even a feminization of UL in the population under 20 years of age could be explained by the fact that on the one hand the UL is much earlier in the female subject [31]; The jump in the sex ratio in the geriatric population would be due to the presence at these ages of mainly prostate obstacles which are an important cause of lithiasis very often affecting the lower urinary tract as reported in the literature [6]. The role of profession and educational attainment in lithiasis disease remains controversial in the literature. Our study found a proportion of $28 \%$ of patients with a lower level of education on all lithiasis patients. Possible explanations for this may include differences in diets but also the fact that subjects with a low level of education often perform more physical occupations and are therefore at risk of dehydration [32].

The proportion of patients with the socio-professional status of worker in our study was the highest at $46.7 \%$. Recent studies have shown that LU is much less found in manual workers than in groups with sedentary occupations [29]. 
Low socio-economic level was associated with a high proportion of lithiasis patients.

If several authors in different parts of the globe find similar results [21], yet no explanation could be provided in particular on the biochemical and metabolic process by which psychosocial stress would become a factor responsible for the formation of urolithiasis [30]. On the other hand, Yasui et al. found a higher frequency of lithiasis patients in more affluent populations [33]. It has been found that they are at an increased risk of having chronic metabolic diseases through high calorie intake [32].

In our study the majority of stones were located in the upper urinary tract or $80 \%$ against $20 \%$ in the bladder. Classically, UL in developing countries was of a preferential anatomical localization in the lower urinary tract, especially at the bladder level [34]. In recent years, this localization is more common in the upper urinary tract in the literature [35].

In industrialized countries, an open surgery has become exceptional or almost non-existent given the very favorable results of the minimally invasive means of an endoscopic surgery and Extracorporeal Shock Wave Lithotripsy (ESWL). Currently, surgical indications are reserved only for complex stones after the failure of Percutaneous Nephrolithotomy (PCNL) or laparoscopy [36] [37].

The treatment was surgical in $74.8 \%$ of cases and pharmacological in $25.2 \%$. This would be explained by an insufficiency of the technical platform and probably the significant presence of the complex shape (the coralliform and bladder stones of a large size).

As this study is retrospective, the absence of some information did not allow looking for risk factors for urolithiasis. The same applies to the morpho-constitutional analysis of urolithiasis. However, it nevertheless provides an idea of the profile of the patient suffering from urolithiasis.

\section{Conclusion}

$\mathrm{UL}$ is a major public health problem due to its increasing prevalence. It mainly affects young adults. As in other sub-Saharan African countries, the lithogenic risk in Congo is associated with the male sex and being overweight. It is seen especially in the working population and those of a high socio-economic level. Lithiasis recurrence affects nearly one in five patients.

\section{Conflicts of Interest}

The authors declare no conflicts of interest regarding the publication of this paper.

\section{References}

[1] Raheem, O.A., Khandwala, Y.S., Sur, R.L., Ghani, K.R. and Denstedt, J.D. (2017) Burden of Urolithiasis: Trends in Prevalence, Treatments, and Costs. European Urology Focus, 3, 18-26. https://doi.org/10.1016/j.euf.2017.04.001

[2] Daudon, M., Traxer, O., Lechevallier, E. and Saussine, C. (2008) Épidémiologie des 
lithiases urinaires. Progrès en Urologie, 18, 802-814. https://doi.org/10.1016/j.purol.2008.09.029

[3] Sorokin, I., Mamoulakis, C., Miyazawa, K., Rodgers, A., Talati, J. and Lotan, Y. (2017) Epidemiology of Stone Disease across the World. World Journal of Urology, 35, 1301-1320. https://doi.org/10.1007/s00345-017-2008-6

[4] Kaboré, F.A., Kambou, T., Zango, B., Ouattara, A., Simporé, M. and Lougué, C. (2013) Épidémiologie d'une cohorte de 450 lithiases urinaires au CHU Yalgado Ouédraogo de Ouagadougou au Burkina Faso. Progrès en Urologie, 23, 971-976. https://doi.org/10.1016/j.purol.2013.04.014

[5] Wathigo, F.K., Hayombe, A. and Maina, D. (2017) Urolithiasis Analysis in a Multiethnic Population at a Tertiary Hospital in Nairobi, Kenya. BMC Research Notes, 10, Article No. 158. https://doi.org/10.1186/s13104-017-2474-3

[6] Odzébé, A.W.S., Bouya, P.A., Berthe, H.J.G. and Omatassa, F.R. (2010) Chirurgie à ciel ouvert de la lithiase urinaire au CHU de Brazzaville: Analyse de 68 cas. Mali Medical, 15, 32-35.

[7] Odzébé, A.W.S., Bouya, P.A., Koutaba, E., Mandavo, C., Ondziel Opara, A.S., Boussoukou Nzikou, V., Ondima, I., Atipo Ondongo, A.M., Banga Mouss, R. and Mbika Cardorelle, A. (2015) Lithiase urinaire chez l'enfant au centre hospitalier universitaire de Brazzaville. Uro'Andro, 1, 183-187.

[8] Ondziel Opara, A.S., Odzébé, A.W.S., Ondongo Atipo, A.M., Banga Mouss, R.B., Dimi, Y., Otsasso Okomiko, D.M. and Bouya, P.A. (2019) Lithiase du haut appareil urinaire: Aspects épidémiologiques, diagnostiques et thérapeutiques à propos de 240 cas au centre hospitalo-universitaire de Brazzaville, Congo. Health Sciences and Disease, 20, 60-63.

[9] Galobardes, B., Shaw, M., Lawlor, D.A., Lynch, J.W. and Davey Smith, G. (2006) Indicators of Socioeconomic Position (Part 2). Journal of Epidemiology \& Community Health, 60, 95-101. https://doi.org/10.1136/jech.2004.028092

[10] Romero, V., Akpinar, H. and Assimos, D.G. (2010) Kidney Stones: A Global Picture of Prevalence, Incidence, and Associated Risk Factors. Reviews in Urology, 12, 86-96.

[11] Scales Jr., C.D., Smith, A.C., Hanley, J.M. and Saigal, C.S. (2012) Urologic Diseases in America Project. Prevalence of Kidney Stones in the United States. European Urology, 62, 160-165. https://doi.org/10.1016/j.eururo.2012.03.052

[12] Hounnasso, P., Avakoudjo, J., Paré, A., Brahima, K., Ouattara, A., Agounkpé, M., et al. (2015) Symptomatic Urinary Lithiasis: Epidemiology and Management at Urology Department of University Hospital of Cotonou. Open Journal of Urology, 5, 7-12. https://doi.org/10.4236/oju.2015.52002

[13] Zeng, G., Mai, Z., Xia, S., Wang, Z., Zhang, K., Wang, L., et al. (2017) Prevalence of Kidney Stones in China: an Ultrasonography Based Crosssectional Study. BJU International, 120, 109-116. https://doi.org/10.1111/bju.13828

[14] Kumari, A., Dokwal, S., Mittal, P., Kumar, R., Goel, R. and Bansal, P. (2016) An Increase Incidence in Uric acid Nephrolithiasis: Changing Patterns. Journal of Clinical and Diagnostic Research, 10, BC01-BC03.

https://doi.org/10.7860/JCDR/2016/19714.8139

[15] Ziemba, J.B. and Matlaga, B.R. (2017) Epidemiology and Economics of Nephrolithiasis. Investigative and Clinical Urology, 58, 299-306. https://doi.org/10.4111/icu.2017.58.5.299

[16] Berthélémy, S. (2016) Limiter les récidives de lithiases urinaires. Actualités 
Pharmaceutiques, 55, 37-39. https://doi.org/10.1016/j.actpha.2015.11.029

[17] Loumingou, R., Eyeni, T. and Gassongo-Koumou, G. (2019) La lithiase rénale au CHU de Brazzaville aspects métaboliques et nutritionnels. Annales de L'Universite Marien Ngouabi, 19, 46-52.

[18] Mobima, T., Kouandongui Bangue Songrou, F. and Debato, L. (2017) Lithiases urinaires à Bangui (République Centrafricaine): Contribution du couple ASP-échographie et de l'UIV. Journal Africain d' Imagerie Médicale, 9, 175-179.

[19] Ahmad, F., Nada, M.O., Farid, A.B., Haleem, M.A. and Razack, S.M. (2015) Epidemiology of Urolithiasis with Emphasis on Ultrasound Detection: A Retrospective Analysis of 5371 Cases in Saudi Arabia. Saudi Journal of Kidney Diseases and Transplantation, 26, 386-391. https://doi.org/10.4103/1319-2442.152557

[20] Cassell III, A., Jalloh, M., Ndoye, M., Mbodji, M., Gaye, O., Thiam, N.M., et al. (2020) Surgical Management of Urolithiasis of the Upper Tract-Current Trend of Endourology in Africa. Research and Reports in Urology, 12, 225-238. https://doi.org/10.2147/RRU.S257669

[21] Ze Ondo, C., Fall, B., Sow, Y., Thiam, A., Sarr, A. and Ghazal, H. (2018) La lithotripsie extracorporelle: Expérience d'un centre Sénégalais. African Journal of Urol$o g y, 24,319-323$. https://doi.org/10.1016/j.afju.2018.03.001

[22] Omisanjo, O., Bioku, M., Williams, O., Akinola, O., Balogun, F. and Ikuerowo, S. (2019) A 5-Year Review of the Presentation and Management of Urolithiasis in a Nigerian Teaching Hospital. Journal of Surgery, 7, 143-147. https://doi.org/10.11648/j.js.20190705.16

[23] Golaz, V., Nowik, L. and Sajoux, M. (2012) L'Afrique, un continent jeune face au défi du vieillissement. Population \& Sociétés, No. 491, 1-4. https://doi.org/10.3917/popsoc.491.0001

[24] Ketabchi, A.A. and Aziziolahi, G.A. (2008) Prevalence of Symptomatic Urinary Calculi in Kerman, Iran. Urology Journal, 5, 156-160.

[25] Abbassene, F., Maizia, A., Messaoudi, N., Bendahmane, L., Boukharouba, H., Daudon, M., et al. (2020) Lithiase urinaire chez l'adulte dans l'ouest algérien: A propos de 1104 cas. La Tunisie médicale, 98, 396-403.

[26] El Habbani, R., Chaqrounea, A., Sqalli Houssaini, T., Arrayhani, M., El Ammari, J., Dami, F., et al. (2016) Étude épidémiologique sur les calculs urinaires dans la région de Fès et sur le risque de récidive. Progrès en Urologie, 26, 287-294. https://doi.org/10.1016/j.purol.2016.02.004

[27] Lieske, J.C., Rule, A.D., Krambeck, A.E., Williams, J.C., Bergstralh, E.J., Mehta, R.A., et al. (2014) Stone Composition as a Function of Age and Sex. Clinical Journal of the American Society of Nephrology, 9, 2141-2146. https://doi.org/10.2215/CJN.05660614

[28] Kaulanjan, K., Cerruti, A., Galantine, V., Laine, C., Rose Dite Modestine, J. and Gourtauda, G. (2018) Épidémiologie de la lithiase urinaire aux Antilles françaises: Étude rétrospective monocentrique. Progrès en Urologie, 28, 114-119. https://doi.org/10.1016/j.purol.2017.10.005

[29] Fisang, C., Anding, R., Müller, S.C., Latz, S. and Laube, N. (2015) Urolithiasis-an Interdisciplinary Diagnostic, Therapeutic and Secondary Preventive Challenge. Deutsches Arzteblatt international, 112, 83-91. https://doi.org/10.3238/arztebl.2015.0083

[30] Castiglione, V., Jouret, F., Bruyère, O., Dubois, B., Thomas, A. and Waltregny, D. (2015) Épidémiologie de la lithiase urinaire en Belgique sur base d'une classification 
morphoconstitutionnelle. Néphrologie \& Thérapeutique, 11, 42-49.

https://doi.org/10.1016/j.nephro.2014.08.003

[31] Liu, Y., Chen, Y., Liao, B., Luo, D. and Wang, K. (2018) Epidemiology of Urolithiasis in Asia. Asian Journal of Urology, 5, 205-214.

https://doi.org/10.1016/j.ajur.2018.08.007

[32] Arzoz-Fabregas, M., Roca-Antonio, J., Ibarz-Servio, L., Jappie-Mahomed, D. and Rodgers, A. (2017) Stress-Stones-Stress-Recurrent Stones: A Self-Propagating Cycle? Difficulties in Solving This Dichotomy. Urolithiasis, 45, 515-524.

https://doi.org/10.1007/s00240-017-0970-5

[33] Yasui, T., Iguchi, M., Suzuki, S. and Kohri, K. (2008) Prevalence and Epidemiological Characteristics of Urolithiasis in Japan: National Trends between 1965 and 2005. Urology, 71, 209-213. https://doi.org/10.1016/j.urology.2007.09.034

[34] Djelloul, Z., Djelloul, A., Bedjaoui, A., Kaid-Omar, Z., Attar, A. and Daudon, M. (2006) Lithiase urinaire dans l'Ouest algérien: Étude de la composition de $1354 \mathrm{cal}-$ culs urinaires en relation avec leur localisation anatomique, l'âge et le sexe des patients. Progrès en Urologie, 16, 328-335.

[35] Daudon, M. (2009) Épidémiologie actuelle de la lithiase rénale en France. Annales d Urologie, 39, 209-231. https://doi.org/10.1016/j.anuro.2005.09.007

[36] Saussine, C., Lechevallier, E. and Traxer, O. (2008) Lithiase urinaire et laparoscopie: Traitement des calculs du rein (hors anomalies fonctionnelles ou anatomiques). Progrès en urologie, 18, 938-942. https://doi.org/10.1016/j.purol.2008.09.006

[37] Doizi, S., Raynal, G. and Traxer, O. (2015) Évolution du traitement chirurgical de la lithiase urinaire sur 30 ans dans un CHU. Progrès en Urologie, 25, 543-548.

https://doi.org/10.1016/j.purol.2015.05.002 